\title{
Cardiac findings in children with juvenile Dermatomyositis at disease presentation
}

Serdar Cantez ${ }^{1}$, Gil J. Gross ${ }^{2}$, lan MacLusky ${ }^{3}$ and Brian M. Feldman ${ }^{4^{*}}$

\begin{abstract}
Background: Juvenile Dermatomyositis (JDM) is a pediatric vasculopathy characterized primarily by skin and muscle involvement. Cardiac findings have been reported in children with JDM but have rarely been investigated in detail.

Methods: We aimed to describe the relevant clinical and laboratory cardiac findings of a cohort of patients with JDM, followed at one centre, at disease diagnosis.

Results: We performed a retrospective review of 105 patients with JDM, followed from 1991 to 2007. Six of 70 patients ( $9 \%, 6 \%$ of the entire cohort) had abnormal electrocardiographic (ECG) findings, while 26 of 54 patients (48\%, 25\% of the entire cohort) had abnormal echocardiographic (echo) findings. Many of these findings were either mild or unlikely to be a result of JDM.

Conclusions: Our findings suggest that cardiac abnormalities at JDM disease onset are frequently seen, but are rarely significant findings due to disease; however, JDM patients should be considered for screening for cardiac disease as late cardiac complications are well recognized.
\end{abstract}

Keywords: Juvenile dermatomyositis, Heart disease, Screening

\section{Background}

Juvenile Dermatomyositis (JDM) is characterized by a small vessel vasculopathy affecting children, characterized primarily by skin and muscle involvement. The etiology of JDM is not yet known [1]. Typical clinical findings of JDM include proximal muscle weakness, heliotrope rash, Gottron's papules, nail fold capillary changes, skin calcifications and swallowing difficulties [2].

Cardiac abnormalities, sometimes serious, have been reported among the less common findings in JDM patients [2]. For example, Ravelli et al. have published long-term outcome and prognostic factors for JDM patients [3]. From Europe and Latin America 27 centers participated in this multicentre study, and 490 patients' data was collected. They found that the cumulative frequency of damage to the cardiovascular system was $2.9 \%$ for 445 patients. Specific cardiac pathology and/or ECG and echo findings were not described in that study.

\footnotetext{
* Correspondence: brian.feldman@sickkids.ca

${ }^{4}$ Department of Pediatrics, Faculty of Medicine, and the Institute of Health Policy, Management \& Evaluation, the Dalla Lana School of Public Health, University of Toronto, Division of Rheumatology, The Hospital for Sick Children, Toronto, Canada

Full list of author information is available at the end of the article
}

Additionally, Pachman et al. reported a cohort of 21 patients with JDM. They found that 10 of 20 children had ECG abnormalities [4]. ECG changes were also examined in a study of 61 Korean juvenile and adult dermatomyositis patients [5]. In this study, ECG abnormalities were present in 6 of 14 JDM patients (37.5\%); 3 patients had right bundle branch block and another 3 had ST changes. In a further study, Rider et al. aimed to validate the myositis damage index (MDI) [6]. In this article, they evaluated both adult polymyositis (PM) patients and JDM patients. Cardiovascular damage was more common in patients with PM than JDM; for the children, $2.8 \%$ had hypertension, and $0.7 \%$ had ventricular dysfunction.

ECG and echo changes have been recently investigated in a case-control study from Norway [7]. Sixty-one patients with an age and sex matched control group of healthy individuals were enrolled. This study aimed to compare cardiac findings of JDM patients with controls. Patients' ECG and echo findings were investigated an average of 16.8 years after the disease diagnosis. In this study 7 patients developed pericarditis, 12 had hypertension, defined as systolic blood pressure $>140 \mathrm{mmHg}, 10$ 
patients had abnormal ECG findings (3 poor R-wave progression, 2 left ventricular hypertrophy, 2 right bundle branch block, one pathological Q-wave, one P pulmonale and one prolonged QTc). Using a similar design, the same group showed that heart rate variability is reduced in JDM patients (followed a median 13.5 years after disease diagnosis) [8], and that long-axis strain was reduced (a marker of systolic dysfunction on echo) in JDM patients followed a median of 16.8 years after diagnosis [9].

Cardiac disease may be serious in JDM and may be a cause of death. In a large series of North American children, heart disease contributed to mortality in 3 of 17 deaths in 329 patients. However, only 1 death (a child with myocarditis) appeared to be directly caused by cardiac disease [10].

Although the Norway studies are very important for demonstrating damage during follow-up, they do not give us information about cardiac findings at onset (the period when disease activity is often the highest). Early cardiac findings in JDM have rarely been investigated in detail; we therefore asked, what is the frequency of ECG and/or echo abnormalities seen at disease diagnosis in children with JDM?

\section{Methods}

This study was approved by the Research Ethics Board at The Hospital for Sick Children, Toronto (SickKids). In our institution, every suspected JDM patient undergoes a detailed physical examination and a series of laboratory investigations including, for many, a cardiac work-up with electrocardiogram (ECG) and echocardiogram (echo).

We reviewed 105 patients newly diagnosed and followed at SickKids between 1991 and 2007. At each patient's initial admission and/or first consultation visit, demographic data was noted, detailed physical examination including heart rate, blood pressure, skin examination, muscle weakness assessment and laboratory investigations were recorded, most often including a 12lead ECG and standard transthoracic two-dimensional, M-mode, and Doppler echo assessment. All patients have been followed by a single pediatric rheumatologist, in a specialized JDM Clinic (BMF), and all have been treated according to our published standardized treatment plan [11].

For this retrospective study, demographic data and clinical findings, ECG and echo findings were obtained from clinical charts, rheumatology and cardiology clinic databases. All ECG and echo findings were reviewed by a single experienced pediatric cardiologist (GG). Heart rhythm, PR interval, corrected QT interval (QTc) and QRS duration were re-measured.
A standardized protocol had been used for all echocardiographic examinations [12]. For interpretation, we used institutional standardized z-scores, similar to those published [13], which our group has used in many publications. ECG standards followed previously published guidelines [14].

Descriptive statistics have been used to present our findings (proportions for categorical variables, means and medians with measures of spread as appropriate). Calculations were done with DataDesk 8.0.0 (Data Description, Inc., Ithaca, NY) and Microsoft Excel 15.35 (Microsoft, Redmond, WA).

\section{Results}

105 patients (72 female) were included. Median age at the time of diagnosis was 6.9 years (range 2.0-17.6 years). Median time of follow up, at the time of our review, was 10.2 years ( 7 months -15.8 years). (Table 1 ).

Electrocardiograms were available for 69 patients. Thirty-six patients either did not have ECGs done, or the ECG was no longer retrievable.

Six patients had abnormal ECG findings (9\%). QTc findings for all 69 patients were as follows: mean $416 \mathrm{~ms}$, range of values $370-509 \mathrm{~ms}$. QTc was abnormally prolonged in 5 patients. (Mean abnormal QTc was $462 \mathrm{~ms}$.) Mean PR interval was $131 \mathrm{~ms}$ (94-214 ms). Mean QRS duration was $78.3 \mathrm{~ms}$ (56-112 ms). One patient had prolonged PR interval and wide QRS. (This patient also had moderate pulmonary insufficiency and mitral regurgitation by echo.)

Echo was available for 52 patients, of which 26 were normal (Table 2). Three patients had pericardial effusions; one of them was small and one was considered "trivial". Isolated tricuspid regurgitation was seen in 3 patients. Six patients had tricuspid regurgitation combined with

\section{Table 1 Demographics}

\begin{tabular}{ll}
\hline$N$ & 105 (72 girls) \\
\hline Median (range of values) age at diagnosis, years & 6.9 (2.0-17.6) \\
Median (range of values) follow-up time, years & 10.2 (0.6-15.8) \\
Diagnosis & \\
JDM & 102 \\
Hypomyopathic JDM & 1 \\
Overlap myositis & 1 \\
Polymyositis & 1 \\
Number of Patients with ECG & 69 \\
Normal & 63 \\
Abnormal & 6 \\
Number of Patients with ECHO & 52 \\
Normal & 26 \\
Abnormal & 26 \\
\hline
\end{tabular}


Table 2 ECG and ECHO Abnormalities

\begin{tabular}{|c|c|c|}
\hline Abnormality & Number & Percent \\
\hline \multicolumn{3}{|l|}{ ECG } \\
\hline Normal & 63 & 91.3 \\
\hline Prolonged QTC & 5 & 7.2 \\
\hline Prolonged PR + wide QRS & 1 & 1.4 \\
\hline \multicolumn{3}{|l|}{$\mathrm{ECHO}$} \\
\hline Normal & 26 & 50.0 \\
\hline THLAA & 1 & 1.9 \\
\hline PER EFF & 3 & 5.8 \\
\hline$T R+P I$ & 6 & 11.5 \\
\hline$T R+P I+M R$ & 1 & 1.9 \\
\hline TR & 3 & 5.8 \\
\hline ASD & 1 & 1.9 \\
\hline VSD & 1 & 1.9 \\
\hline $\mathrm{Al}+\mathrm{Pl}$ & 1 & 1.9 \\
\hline$P D A+D I L L A+L V$ & 1 & 1.9 \\
\hline $\mathrm{Pl}$ & 3 & 5.8 \\
\hline$M V P+M R+P I$ & 1 & 1.9 \\
\hline$\uparrow R V E D$ dimension & 1 & 1.9 \\
\hline$\uparrow I V R T+T R+P I$ & 1 & 1.9 \\
\hline $\mathrm{PI}+\mathrm{MR}$ & 1 & 1.9 \\
\hline$\downarrow$ PV D wave vel. & 1 & 1.9 \\
\hline
\end{tabular}

pulmonary insufficiency. One patient had both aortic and pulmonary insufficiency. Isolated pulmonary insufficiency was seen in 3, all considered trivial. One patient had mitral valve prolapse and mild mitral regurgitation and pulmonary insufficiency. Mitral regurgitation with pulmonary insufficiency was seen in one patient. One patient was found to have increased right ventricular end diastolic dimension. Another patient had decreased pulmonary vein D-wave velocity. Four patients had conditions that are almost certainly incidentally identified congenital abnormalities, and therefore unrelated to JDM: patent ductus arteriosus (PDA) with dilated left atrium and left ventricle, tubular hypoplasia of left aortic arch (THLAA), atrial septal defect, and ventricular septal defect. Ventricular function (left ventricular ejection fraction) was normal in all.

The cardiac findings are listed along with the clinical features of JDM at diagnosis in Table 3.

\section{Discussion}

Our results suggest that many JDM patients have abnormal ECG and echo results at first presentation. Some of the findings, though, were mild and unlikely to be related to the underlying disease; for example, mild tricuspid regurgitation and/or pulmonary insufficiency are common and not necessarily abnormal. Although none of our patients presented with clinically serious cardiac dysfunction, and many of our patients had findings commonly seen in children without JDM, we believe that the high incidence of abnormalities is a reasonable justification for a cardiac work-up at disease onset. This, coupled with the reported accumulation over time of cardiac damage, suggests to us that careful cardiac monitoring over the disease course should be carried out in JDM patients $[6,7,9]$.

We found more abnormalities at the outset of disease than other authors have seen over the course of the illness. ${ }^{3}$ This is likely because we used laboratory examinations to determine cardiac abnormalities; none of our patients were symptomatic, and none developed clinically meaningful cardiac disease during follow-up (although few had detailed laboratory examinations repeated over time as most were both asymptomatic and had normal heart rates and normal blood pressures for the duration of follow-up).

Our study should be interpreted in the light of possible limitations. Because our cohort goes back to the early 1990s, we have been unable to find some ECG and echo data; some patients did not have these investigations and others went missing. The implications of these

Table 3 JDM measures sorted by cardiac abnormality

\begin{tabular}{|c|c|c|c|c|c|c|c|c|c|c|c|c|c|c|c|c|c|c|}
\hline & & \multicolumn{5}{|c|}{$\begin{array}{l}\text { Manual Muscle } \\
\text { Testing }(/ 10)^{\mathrm{a}}[15]\end{array}$} & \multicolumn{3}{|c|}{ Heliotrope rash } & \multicolumn{3}{|c|}{ Gottron's sign/papules } & \multicolumn{3}{|c|}{ Other skin rash } & \multicolumn{3}{|c|}{ Nail fold capillaries } \\
\hline & & $n$ & median & IQR & $\min$ & $\max$ & $\mathrm{n}$ & Abnormal & $\%$ & $n$ & Abnormal & $\%$ & $n$ & Abnormal & $\%$ & $n$ & Abnormal & $\%$ \\
\hline \multirow[t]{4}{*}{$\mathrm{ECHO}$} & All $(n=105)$ & 98 & 8 & 2 & 0 & 10 & 105 & 69 & 65.7 & 104 & 79 & 76.0 & 98 & 76 & 77.6 & 97 & 82 & 84.5 \\
\hline & Abnormal $(n=26)$ & 26 & 8 & 3.75 & 0 & 10 & 26 & 19 & 73.1 & 26 & 21 & 80.8 & 25 & 19 & 76.0 & 24 & 21 & 87 \\
\hline & Normal $(n=26)$ & 26 & 8 & 2.5 & 2 & 10 & 26 & 18 & 69.2 & 25 & 18 & 72.0 & 26 & 21 & 80.8 & 25 & 23 & 92. \\
\hline & Not done $(n=53)$ & 46 & 8 & 1 & 2 & 10 & 53 & 32 & 60.4 & 53 & 40 & 75.5 & 47 & 36 & 76.6 & 48 & 38 & 79 \\
\hline \multirow[t]{4}{*}{ ECG } & All $(n=105)$ & 98 & 8 & 2 & 0 & 10 & 105 & 69 & 65.7 & 104 & 79 & 76.0 & 98 & 76 & 77.6 & 97 & 82 & \\
\hline & Normal $(n=63)$ & 60 & 8 & 2.25 & 0 & 10 & 63 & 45 & 71.4 & 62 & 49 & 79.0 & 62 & 51 & 82.3 & 61 & 55 & 90 \\
\hline & Abnormal $(n=6)$ & 6 & 8 & 1.5 & 5 & 10 & 6 & 4 & 66.7 & 6 & 6 & 100.0 & 6 & 5 & 83.3 & 6 & 5 & 83. \\
\hline & Not done $(n=36)$ & 32 & 8 & 1.25 & 2 & 10 & 36 & 20 & 55.6 & 36 & 24 & 66.7 & 30 & 20 & 66.7 & 30 & 22 & 73 \\
\hline
\end{tabular}

${ }^{\mathrm{a}}$ As determined by the weakest muscle group at presentation using the 10-point Kendall scale 
missing data are unclear; however, as described above, none of these patients has gone on to have important cardiac morbidity.

\section{Conclusion}

In conclusion, children with new onset JDM have a high frequency of cardiac abnormalities, mostly minor, as determined by ECG and echocardiography. We recommend that a cardiac workup should be considered in the initial workup for every suspected JDM patient.

\section{Abbreviations}

ECG: Electrocardiogram; Echo: Echocardiogram; JDM: Juvenile dermatomyositis; MDI: Myositis damage index; PDA: Patent ductus arteriosus; PM: Polymyositis; QTc: Corrected QT interval; THLAA: Tubular hypoplasia of left aortic arch

\section{Acknowledgements}

Not applicable.

\section{Funding}

Not applicable.

\section{Availability of data and materials}

The datasets generated during and/or analysed during the current study are not publicly available due to privacy and confidentiality reasons.

\section{Authors' contributions}

$\mathrm{SC}$ and $\mathrm{BF}$ contributed to data collection. All authors gave input with design of the study, interpretation of the data, as well as drafting, reviewing and approval of the final manuscript.

\section{Ethics approval and consent to participate}

This study was approved by the Research Ethics Board at The Hospital for Sick Children, Toronto (REB \#1000008690).

\section{Consent for publication}

Not applicable.

\section{Competing interests}

The authors declare that they have no competing interests.

\section{Publisher's Note}

Springer Nature remains neutral with regard to jurisdictional claims in published maps and institutional affiliations.

\begin{abstract}
Author details
${ }^{1}$ Department of Pediatrics, Istanbul University, Istanbul Faculty of Medicine, Istanbul, Turkey. ${ }^{2}$ Department of Pediatrics, University of Toronto, Division of Cardiology, The Hospital for Sick Children, Toronto, Canada. ${ }^{3}$ Department of Pediatrics, University of Ottawa; Division of Respirology, the Childrens' Hospital of Eastern Ontario, Ottawa, Canada. ${ }^{4}$ Department of Pediatrics, Faculty of Medicine, and the Institute of Health Policy, Management \& Evaluation, the Dalla Lana School of Public Health "University of Toronto, Division of Rheumatology, The Hospital for Sick Children, Toronto, Canada.
\end{abstract}

Received: 17 August 2016 Accepted: 3 July 2017

Published online: 11 July 2017

\section{References}

1. Feldman BM, Rider LG, Reed AM, Pachman LM. Juvenile dermatomyositis and other idiopathic inflammatory myopathies of childhood. Lancet. 2008 Jun 28:371(9631):2201-12.

2. Ramanan AV, Feldman BM. Clinical features and outcomes of juvenile dermatomyositis and other childhood onset myositis syndromes. Rheum Dis Clin N Am. [Review]. 2002 Nov;28(4):833-857.

3. Ravelli A, Trail L, Ferrari C, Ruperto N, Pistorio A, Pilkington C, et al. Longterm outcome and prognostic factors of juvenile dermatomyositis: a multinational, multicenter study of 490 patients. Arthritis Care Res (Hoboken). [Comparative Study Multicenter Study Research Support, Non-U. S. Gov't]. 2010 Jan 15;62(1):63-72.

4. Pachman LM, Cooke N. Juvenile dermatomyositis: a clinical and immunologic study. J Pediatr. [Research Support, U.S. Gov't, P.H.S.] 1980 Feb;96(2):226-234

5. Na SJ, Kim SM, Sunwoo IN, Choi YC. Clinical characteristics and outcomes of juvenile and adult dermatomyositis. J Korean Med Sci. [Case Reports]. 2009 Aug;24(4):715-721

6. Rider LG, Lachenbruch PA, Monroe JB, Ravelli A, Cabalar I, Feldman BM, et al. Damage extent and predictors in adult and juvenile dermatomyositis and polymyositis as determined with the myositis damage index. Arthritis Rheum. [Comparative Study Research Support, N.I.H., Extramural Research Support, Non-U.S. Gov't]. 2009 Nov:60(1 1):3425-3435.

7. Schwartz T, Sanner H, Husebye T, Flato B, Sjaastad I. Cardiac dysfunction in juvenile dermatomyositis: a case-control study. Ann Rheum Dis. [Research Support, Non-U.S. Gov't]. 2011 May;70(5):766-771.

8. Barth Z, Nomeland Witczak B, Schwartz T, Gjesdal K, Flato B, Koller A, et al. In juvenile dermatomyositis, heart rate variability is reduced, and associated with both cardiac dysfunction and markers of inflammation: a cross-sectional study median 13.5 years after symptom onset. Rheumatology (Oxford). 2016;55(3): 535-43. doi:10.1093/rheumatology/kev376. Epub 2015 Oct 24.

9. Schwartz T, Sanner H, Gjesdal O, Flato B, Sjaastad I. In juvenile dermatomyositis, cardiac systolic dysfunction is present after long-term follow-up and is predicted by sustained early skin activity. Ann Rheum Dis. 2014;73(10):1805-10.

10. Huber AM, Mamyrova G, Lachenbruch PA, Lee JA, Katz JD, Targoff IN, et al. Early illness features associated with mortality in the juvenile idiopathic inflammatory myopathies. Arthritis Care Res (Hoboken). 2014;66(5):732-40.

11. Ramanan AV, Campbell-Webster N, Ota S, Parker S, Tran D, Tyrrell PN, et al. The effectiveness of treating juvenile dermatomyositis with methotrexate and aggressively tapered corticosteroids. Arthritis Rheum. 2005;52(11):3570-8.

12. Lai WW, Geva T, Shirali GS, Frommelt PC, Humes RA, Brook MM, et al. Guidelines and standards for performance of a pediatric echocardiogram: a report from the task force of the pediatric Council of the American Society of echocardiography. J Am Soc Echocardiogr. 2006;19(12):1413-30.

13. Daubeney PE, Blackstone EH, Weintraub RG, Slavik Z, Scanlon J, Webber SA. Relationship of the dimension of cardiac structures to body size: an echocardiographic study in normal infants and children. Cardiol Young. 1999;9(4):402-10.

14. Davignon A, Rautaharju P, Boisselle E, Soumis F, Megelas M, Choquette A. Normal ECG standards for infants and children. Pediatr Cardiol. 1980;1(2):123-31.

15. IMACS. Manual muscle testing procedures. [cited 2017 June 29]; Available from: https://www.niehs.nih.gov/research/resources/assets/docs/muscle grading_and_testing_procedures_508.pdf. Accessed 7 July 2017.

Submit your next manuscript to BioMed Central and we will help you at every step:

- We accept pre-submission inquiries

- Our selector tool helps you to find the most relevant journal

- We provide round the clock customer support

- Convenient online submission

- Thorough peer review

- Inclusion in PubMed and all major indexing services

- Maximum visibility for your research

Submit your manuscript at www.biomedcentral.com/submit
Biomed Central 